\title{
The effect of stress on the teaching performance of primary school teachers in Tsirang Dzongkhag
}

\author{
Cheku ${ }^{1,}$ Nidup Wangdi ${ }^{2}$
}

\author{
${ }^{1}$ Principal, Rangthangling Primary School, Tsirang, Bhutan \\ ${ }^{2}$ Principal, Phuentenchu Primary School, Tsirang, Bhutan \\ Received: 03 Aug 2021; Received in revised form: 07 Sep 2021; Accepted: 15 Sep 2021 \\ (C2021 The Author(s). Published by TheShillonga. This is an open access article under the CC BY license \\ (https://creativecommons.org/licenses/by/4.0/)
}

\begin{abstract}
This study aims to determine the reasons for stress among teachers of primary schools in Tsirang Dzongkhag in Bhutan. The study sought to find out how work-related stress could affect the productivity of teachers of Tsirang Dzongkhag in the dispensation of quality education. The research included both quantitative and qualitative methods. The target population was a hundred and ten (110) teachers from the twelve (12) public schools in Tsirang Dzongkhag. However, a sample of six (6) teachers was selected using random sampling for the qualitative data using Focus Group Discussion (FGD).
\end{abstract}

Data was gathered from both primary and secondary sources, and descriptive statistics were used to analyse it. The researchers correlated the variables using the Scientific Package for Social Scientists (SPSS) for quantitative data and $M A X Q A D$ for qualitative data. The results of the analysis were presented using frequency tables, bar graphs, and pie charts. The study produced a research report on the primary elements that cause stress among teachers in Tsirang Dzongkhag and highlight gaps that need to be filled by other researchers.

This study found that the most common source of occupational stress for teachers was workload, followed by student misbehaviour and frequent policy and program changes. Respondents also proposed reducing workload by maintaining a teacher-student ratio of 1:24, minimising teacher roles and responsibilities with appropriate teaching staff, review of SPMS, IWP, BPST, and leadership commitment to employee-related issues to relieve stress.

Keywords-Teachers Performance, Job Stress, Stress Management, education policy and leadership style.

\section{INTRODUCTION AND THE BACKGROUND}

Teaching has long been regarded as one of the most stressful occupations, with several studies indicating that teachers worldwide are subjected to various forms of stress (Hartney, 2008; Kyriacou, 2001). Teacher stress is a wellpublicised issue, yet there is little agreement across professional groups about what causes it or how to address it. According to a review of international studies, teacher stress is a natural phenomenon. High levels are reliably connected with various causal factors, including those inherent to teaching, individual sensitivity, and systemic impacts.

Lim (2014) claims that teachers are the most influential professionals for a country's future. Within any country's education system, teachers have a vital position, as the success of educational institutions is primarily dependent on teachers; their performance is a fundamental concern of all educational institutions (Suyanto et al., 2021). They help create great students. Research shows that an inspiring and informed teacher is the most important school-related factor influencing student achievement, so it is critical to pay close attention to how we support both new and experienced educators.

Teachers have many roles in carrying out in their daily schedules. Their roles may include facilitator, planner, curriculum developer, information provider, role model, guidance, and resource developer. To do all the mentioned activities, teachers work daily with students; cope with numerous problems, student misbehaviours and students with different learning abilities, accountability for student performance, classroom management and discipline, supervisory role, insufficient funding and lack of personal support. Moreover, teachers have to perform a lot of work after they reach home, like lesson planning, correcting the notebooks, preparing teaching-learning materials, and reflecting on their daily teaching. They don't have time to 
communicate and enjoy themselves with their family. Without the support from the relevant stakeholders and their required skills, they cannot perform all these roles effectively. Instead, confronting lots of inevitable challenges are unavoidable. 'Stress' is one of the concerning factors that will always be a part of the teaching profession when balancing these many roles. Ekundayo and Kolawole (2013, p. 311) had found out in their studies that the stress experienced by the teachers is the most prominent factor affecting the level of teaching performance.

Excessive stress might lead to health issues. Stress can also impair one's capacity to function at their best (Chan, 1998). Stress can harm one's performance and quality of life. The consequences of stress are undeniably numerous. They include increased heart rate, faster breathing or held breath, tightening muscles to prepare to fight or flee, directing blood to the brain and major muscles (away from digestion, hands/feet, and reproductive organs), releasing stress hormones such as cortisol and adrenaline, slowing or stopping digestion, causing the brain to be more reactive/less thoughtful, increasing perspiration, and lowering the immune system (Guglielmi and Tatrow, 1998). Competitive athletes have long been aware of the harmful consequences of stress on their performance, according to Kobasa et al. (1985). In a track and field sprint, tight muscles can reduce the time by fractions of a second. This can make all the difference in whether you win or lose an event. In a UNESCO study, Increasing Teacher Effectiveness, Lorin (2015) argued that students' assigned ineffective teachers have lower gains in academic achievement than those taught by a sequence of several highly effective teachers.

Learning to control stress responses and get out of one's way, according to Scheier and Carver (1985), has saved companies money, increased production, encouraged creativity, enabled teams to communicate more effectively, reduced the anxieties that come with change, accelerated professional learning and development, and even reduced accidents and harassment claims. Any company wants to save money, reduce turnover, increase sales and productivity, and promote employee morale. It should consider the cost-benefit of stress management training or coaching. As a result, implementing a holistic professional development strategy to improve teachers' stress management and resilience will have a major impact, resulting in lower teacher burnout, greater teaching quality and effectiveness, and increased teacher retention.

\subsection{Statement of the problem}

According to Tashi (2014, p.73), teaching is a popular career choice in Bhutan; however, it is increasingly described as a high-stress profession. Both are experienced and are keen to retire early." Similarly, Karaj \& Rapti (2013, p.14) state, "It is common for teachers to experience higher stress levels than other professional groups." Stress is a well-established notion in the psychological literature, and teaching, in particular, is well acknowledged as a very stressful job (Hartney et al., 2009). According to a recent study, most teacher preparation programs do not incorporate stress management (Harris, 2011).

Knowing that stress will always be present, there is a need to find out the main sources of stress among primary teachers of Tsirang and its relationship with the teaching performances. Most of the teachers in the primary schools work in very pitiable working conditions without having adequate modern facilities. Several studies have shown that job stress negatively affects employee performance considering the various factors, especially employee job satisfaction. Recent studies have confirmed this (Ahmed \& Ramzan, 2013) that show a negative correlation between job stress and employee performance. A similar study revealed that workload, role conflict, and inadequate monetary reward are prime sources of stress that decrease employee performance. Furthermore, Kandala and Ramchandram (2021) investigated the impact of occupational stress among teachers. They found that stress causes teachers to be absent, increases the tendency to quit, and is less likely to pursue a teaching career, hence negatively correlated.

Additionally, the need to improve education quality has become a priority for education policymakers as there is widespread public concern over the perceived decline in education quality. The latter has become a hot topic of discussion at seminars, meetings, and even in the national assembly. More importantly, His Majesty's 'Kasho' on Education reforms has added more responsibilities to the teachers. This affirms that teachers receive bounteous stress as they are the backbone of the education system where the quality of education hinges on their quality and motivation (Tashi. 2014, p. 72). Most importantly, teachers in Bhutan are also understood as a means to pass on values based on the unique philosophy called Gross National Happiness (GNH).

With the recent COVID 19 globally, the coronavirus pandemic has caused severe disruption in the education sector; schools have been closed for a long time. Online or e-learning has been challenging for both students and teachers. But all these exciting things in the education sector bring us to a sobering reality. When schools closed, and online learning began, many students found themselves unable to afford even a mobile phone from where they could follow the day's lesson and complete 
their assignments. Internet connectivity is a significant problem in the country. The post-pandemic has instead fueled the fire to the teacher's stress and productivity. The New Normal Curriculum (NNC) is a changeover whose time has come. Although, NNC rests on the innovations and speed of the ongoing digital revolution. Many of the primary schools in the country do not have such infrastructures, which might increase teachers' stress.

Furthermore, no conscious link between work stress and its negative impact on productivity has been shown. In light of these issues, the purpose of this study is to highlight the effects of occupational stress on the overall performance of teachers.

\subsection{The purpose of the study}

Although many researchers have found various sources of stress among teachers of different parts of the world, this study will examine only four stress factors and teaching performances among primary teachers of schools of Tsirang Dzongkhag. Thus, this study will find out the main factors causing stress and the effect on teaching performance. These objectives will provide insight into the phenomenon of teacher stress and may lead health educators to understand the occurrence of teacher stress better. The researcher hopes that the information in this proposed research study will provide effective programs that will assist teachers in handling stress more effectively through positive coping mechanisms and have outstanding teaching performances.

More importantly, the policymakers and dealing stakeholders will take the information presented here to plan and work accordingly. There have been so many scholarly publications or journals written recently about job-related stress that one can reasonably conclude that everyone is unhappy and disheartened, especially in the workplace. Management is unwilling to take adequate actions to reduce employee stress as it continues to hover over them. According to Dyck $(2001,52)$, a few job stress factors can impair an employee's quality of life, making an assigned task difficult and stressful for the employee to do regardless of the setting. Many researchers argue that stress at the workplace impacts performance in one way or the other. McTernan (2013) views work-related stress as a leading cause of low productivity in the workplace.

\subsection{The research objectives}

The general objective of this study was to find out the primary sources of teacher stress and its impact on teaching performances. To realise this, the study was guided by the following specific objectives.

- Define the level of work-related stress among the teachers of primary schools under Tsirang

\section{Dzongkhag.}

- Identify the main factors causing stress and the effect of the stress on teaching performance

- Describe the most critical consequences of the work-related stress among the teachers of primary schools of Tsirang Dzongkhag.

- To deliver a set of suggestions and recommendations following the study results.

\section{The research questions}

The study will seek to answer the following questions during the research:

1. How does stress affect the teaching abilities of primary school teachers in Tsirang Dzongkhag?

2. To what extent do intrinsic teaching characteristics (workload, classroom discipline and leadership style and Education system and policy) influence teachers' stress levels?

3. What are the sources of stress for primary school teachers in Tsirang Dzongkhag?

\subsection{Hypothesis}

The hypothesis of this research is:

H1: Teacher stress factors have significant impact job performance

\subsection{The significance of the study}

The teacher role is very fundamental for the success of the educational process. The adverse effects of the stress at work on the teachers' productivity, attitude and interactions with workmates. Thus, this paper examined this stress to find the appropriate means and procedures to reduce or resolve it. Teacher's rehabilitation should not be limited to periodical discussions such as the School-Based In-service Programme (SBIP) and training sessions. It should instead include every physical and mental aspect. Hence, there is a need to maintain teacher performance in its best form to perform duties and responsibilities and keep up with the latest educational updates.

Thus, this study sought to address stress at work and its implications. The study puts forward some sensible suggestions to save the teacher from stressful settings and burnout, which would lead to positive outcomes of his performance in the educational process. More importantly, the policymakers and dealing stakeholders will take the information presented here to plan and work accordingly.

\section{METHODOLOGY}

\subsection{Research design}

The study combined both quantitative and qualitative types 
of designs. It aims at getting numerical information and a description of people's feelings, perspectives, opinions, attitudes, and experiences. A descriptive research survey was also adopted to focus on a qualitative method to understand how students' misbehaviour, workload, teachers' relationship, and performance management system cause stress. Researchers had identified many causes for anxiety. But this study had carried out an indepth analysis on four causes and their effect on teaching performances. The research study also focused on applied research to gain many insights on the topic.

\subsection{Research instrument}

Both primary and secondary data sources were explored. Preliminary data was collected from every teacher from the primary school of Tsirang Dzongkhag via questionnaire and involved two teachers from each school as respondents in Focus Group Discussion (FGD) in gaining many insights, capturing the information that could not be captured has been collected through questionnaires and triangulating the results on the topic. Questionnaires captured both qualitative and quantitative data, while the FGDs captured qualitative data, which added value to the research findings (Makasa, 2013). FGDs had helped to add more value to the results of the questionnaires because they involved quality interaction between the researcher and the respondents. In this regard, FGDS was used to elicit detailed information about personal feelings, perceptions and opinions.

Timely observation in the schools was also carried out to verify the facts and responses of the subjects and authenticate information. Researchers have explored secondary data sources (past literature) to analyse new findings and possible new solutions to the problem under study. Since not many studies have been done in the Bhutanese context, the primary data was collected through questionnaires and focus group discussion on contextualising the problem, solutions, and recommendations in the Bhutanese context.

Data were collected using standardised questionnaires survey, focus group discussion, and observations for the study's purpose. Questionnaires were distributed to all the primary teachers of Tsirang Dzongkhag. The standardised questionnaires were the principal tools in data gathering for the analysis. It had established the four causes of stress and the teachers' teaching performance who are teaching the primary schools of Tsirang Dzongkhag. The questionnaire was intended to examine and measure the causes of stress, as mentioned above.

Similarly, FGD was done with six participants of two schools. The questionnaire survey, as well as FGD, had involved only the teachers. For authentication, observation was carried out in the schools by the enumerator/researcher.

\subsection{Sample size and location}

For this study, a purposive sampling design was used. Given the shortage of time and resources, this technique was feasible in gathering data. All the teachers, irrespective of gender, age, seniority and qualification, were chosen from all the primary schools of Tsirang Dzongkhag. There were 110 teachers, including the school principal, involved in the study. Of the 110 participants selected, only 80 questionnaires have been returned. The researchers have chosen three participants from two primary schools for focus group discussion using random sampling. The study was carried out in August 2021 for all the respondents in the school.

Table: 2.3.1 - Sample size and location

\begin{tabular}{|r|l|l|l|c|c|c|}
\hline \multirow{2}{*}{ SI\# } & \multicolumn{5}{|c|}{ Quantitative sample size } & \multicolumn{2}{c|}{ Qualitative Sample size } \\
\cline { 2 - 7 } & Schools & Dzongkhag & $\begin{array}{l}\text { Category } \\
\text { of sample }\end{array}$ & $\begin{array}{l}\text { No. of } \\
\text { sample }\end{array}$ & $\begin{array}{l}\text { Category of } \\
\text { sample }\end{array}$ & $\begin{array}{l}\text { No. of } \\
\text { sample }\end{array}$ \\
\hline 1 & Sergithang PS* & Tsirang & Teachers & 8 & FGD & 3 \\
\hline 2 & Tsirangtoe CS* & Tsirang & Teachers & 15 & & \\
\hline 3 & Semjong PS & Tsirang & Teachers & 7 & FGD & 3 \\
\hline 4 & Phuentenchu PS & Tsirang & Teachers & 6 & & \\
\hline 5 & Gosarling PS & Tsirang & Teachers & 6 & & \\
\hline 6 & Damphu LSS* & Tsirang & Teachers & 20 & & \\
\hline 7 & Tsholingkhar PS & Tsirang & Teachers & 8 & & \\
\hline 8 & Rangthaling PS & Tsirang & Teachers & 8 & & \\
\hline 9 & Kilkhorthang PS & Tsirang & Teachers & 7 & & \\
\hline
\end{tabular}




\begin{tabular}{|c|l|l|l|c|c|c|}
\hline 10 & Barshong PS & Tsirang & Teachers & 6 & & \\
\hline 11 & Patshaling PS & Tsirang & Teachers & 7 & & \\
\hline 12 & Mendrelgang PS & Tsirang & Teachers & 12 & & \\
\hline \multicolumn{7}{|r|}{ Total sample size }
\end{tabular}

*Primary School * Central School and * Lower Secondary School

\subsection{Method of data analysis}

'Data analysis is a process of making meaningful and valuable conclusions from bulky and jumbled pieces of information obtained during one's investigation of the problem', says Makasa (2013). Thus, to identify whether the dependent variables mentioned in the theoretical framework influence the independent variable by affecting the mediating factor among remote primary teachers or not, the collected data was thoroughly examined and checked for completeness and comprehensibility. The data collected through questionnaires were then summarised, coded and tabulated using SPSS 16 program to do statistical analysis. With this software, frequencies, percentages and means for all the variables were calculated while data gathered through FGDs was analysed using MAXQAD software.

Descriptive statistics mainly, frequencies and percentages were applied to help establish patterns, trends, and relationships and make it easier for the researcher to understand and interpret the study's implications. Pie charts and bar graphs were also made to represent data in a graphical format, which other users could easily use and understand.

\subsection{Limitation of the study}

By using a convenience, non-random sample of primary school teachers, specific generalisations cannot be made about the total population because this sample is not representative of all primary school teachers of Bhutan. Moreover, only one study had been done in the Bhutanese context, and it has minimal information to compare and contrast.

Since participants were asked to respond to items that review past experiences of stress, how they respond may be affected by their memory recall. Also, participants may tend to under-report undesirable results because they do not want to portray the teaching profession in a negative way negatively.

\section{THE CONCEPTUAL FRAMEWORK OR THEORETICAL FRAMEWORK}

\section{Dependent variable}

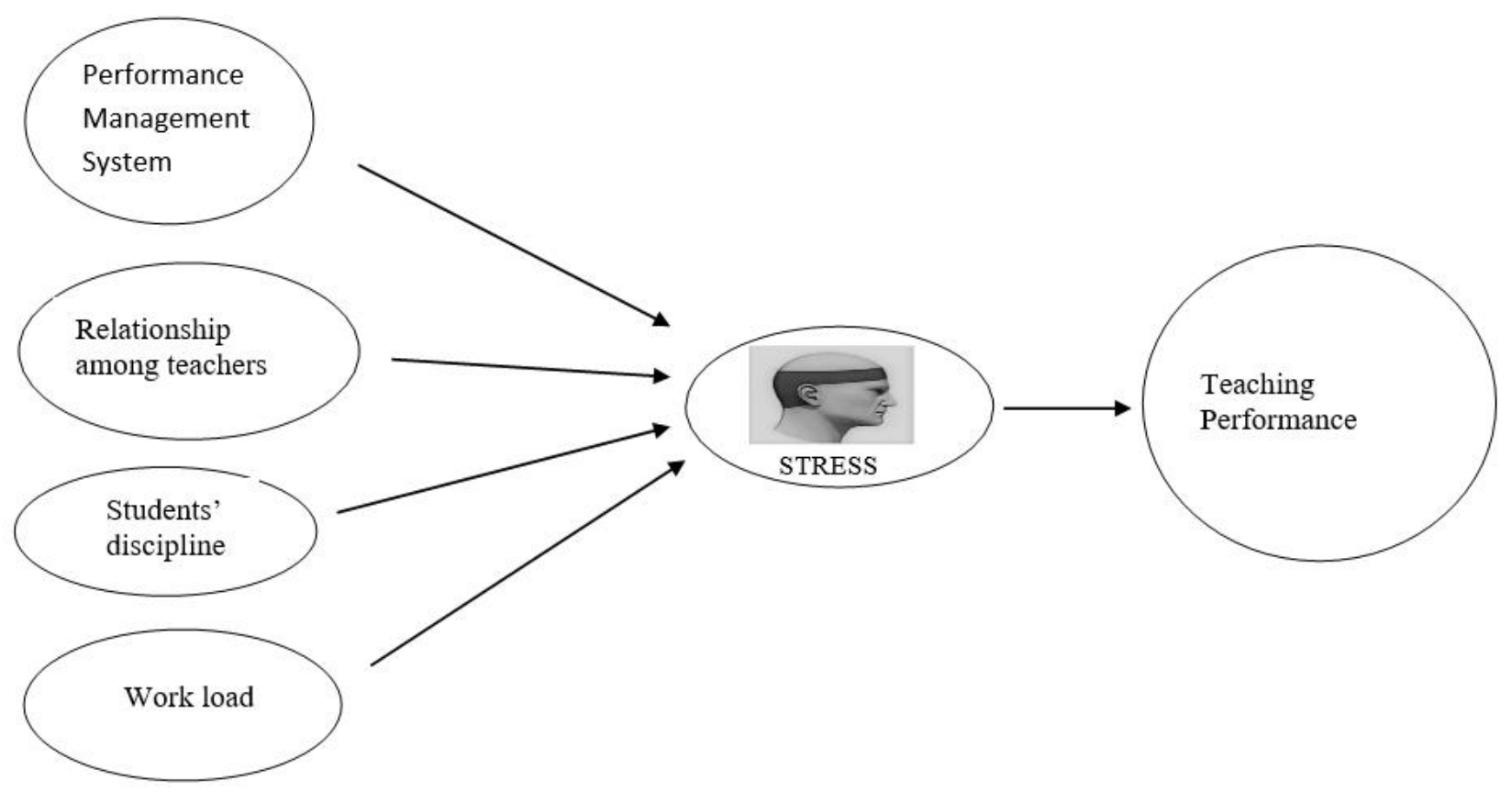

Fig: 3 - Conceptual framework diagram 


\section{LITERATURE REVIEW}

Mathews (2017, p. 17) defines stress as pressure or tension experienced by an individual when interacting with the environment where stimuli-response is enlisted. In responding to stress or an individual exhibits a physiological response to a potentially harmful external event.

Stress in general and teachers' stress, in particular, is a complex and multifold phenomenon with diverse meanings. However, teacher stress can be defined as the 'experience of unpleasant negative emotions such as anger, frustration, anxiety, depression and nervousness, resulting from some aspect of their work' (Kyriacou as cited in Tashi 2014, p. 71). Teachers are exposed to unwanted environmental factors, either within the educational institution or outside the educational institution. These factors hamper the everyday routine life of teachers by negatively affecting their performance at work. According to Derogatis (as cited in Nyambongi 2013, p. 1), stress may be defined as a state of psychological pressure influenced by three primary sources: personality mediators, environmental factors and emotional responses.

Many studies have been carried out worldwide to determine the sources of stress among teachers and their effect on teaching performances. Their findings identified fewer rewards, work overload, the existence of too many students, tight institutional policies, poor relationships with bosses and colleagues and minor carrier progression, etc. These factors put pressure on teachers and ultimately causes stress (Boyd, Lewin, \& Sager, 2009; Forlin, 2001; Sharpley, Reynolds, \& Acosta, 1996 as cited in Khan et al., 2012, p. 23). Teacher stress is caused by environmental factors as well as individual characteristics. Major ecological factors include poor working conditions, misbehaviours of students, scarcity of resources, heavy workloads, relationships among teachers and student behaviour. Unique features that cause stress include gender, age, personality, and coping with the situations (Guglielmi \& Tatrowas cited in Sprenger 2011, p. 1). Most of the researchers had inferred primary sources of stress as: 'workload', 'bad relation among colleagues', 'bad behaviours of pupils 'and' poor working conditions. But this study will specifically focus only on four common factors mentioned below, prevailing among Bhutanese teachers.

\subsection{Students' Misbehavior}

Haroun and O'hanlon (as cited in Alghaswyneh 2011, p.152) defined students' misbehaviour as anti-social behaviour and varied upon teachers' expectations of how students behave in the classroom. Most of the students, especially in the primary schools of Bhutan, not only go to schools untidily but also talk out of turn, be inattentive, lack motivation, move out of their seat, make inappropriate banter and non-verbal noise, pray to leave the classroom frequently and bully among each other. These multiple disruptive and undisciplined behaviours lead to many problems and potential sources of stress for the teachers besides performing very poorly in the performances. The ban on corporal punishment and the influence of western culture through television and social media added fuel to the fire in increasing the pupil's misbehaviour in the classroom. These negative behaviours indeed impact negatively on educators and thus resulting in stress and the decline in work performance (Naidoo et al. 2013, p. 180). The more pupils with emotional/behavioural difficulties there were in the school, the higher the stress levels experienced by the teachers and principals (Darmody and Smyth, 2016)

According to Danham and Kyriacou (as cited in Alghaswyneh 2011,p. 152)

Students' behaviour can be minor and major. Little as arriving late, refusing punishment and not paying attention to the teacher. Significant as verbal abuse and physical aggression towards teachers or other students. According to them, the former appears insignificant as a cause of stress, while the latter is considered more severe.

But practically, both can equally cause stress. For instance, a child arriving late for a time may not be a severe problem. Still, if they repeatedly come late, it is a challenge for the teacher to find the root cause for lateness and make that particular child punctual to interrupt the smooth flow of teaching and a valuable time in learning. Furthermore, some children raise silly questions when the teacher is teaching very interestingly. Doesn't this act irritate teachers? Yes! Although it is a seemingly foolish act, it has numerous effects on teachings. Haroun and O'hanlon (as cited by Alghaswyneh 2011, p. 152) reported some behaviour is considered severe due to frequency since it causes emotionally draining or teachers than for separate, isolated and severe misbehaviour. The repeated misdeeds are also turned serious when teachers reach tolerance level. Thus, the degree of students' misbehaviour may not affect the stress level. In addition, students' being late to school, their failure, and students' not doing homework are minor but cause stress in teachers (Adams 2001; Joseph, 2000 as cited in Eres \& Atanasoska 2011)

In the research done by Alghaswyneh (2011, p. 153) to find teacher stress among Tawjihi teachers in Jordan, students' misbehaviour is one of the distinguishing factors causing tension among the Tawjihi teachers. In the same 
line, 76,7\% agreed that indiscipline among students is one of the sources of stress (Ekundayo and Kolawole 2013, p. 313). Contradictory to this, Eres \& Atanasoska (2011, p. 61) says that stress caused by students' misbehaviour is very minimal.

\subsection{Relationship among colleagues}

Alghaswyneh (2011, p. 147) found out the primary sources of stress related to colleagues; for Tawjihi teachers,' cooperation between colleagues is poor'. His findings could be authentic because teachers are overloaded and do not have enough time to meet with other colleagues to coordinate their work together. They are busy preparing, grading and doing other job-related work. Teachers' schedules are tight. At the same time, they need to cooperate as co-workers and subject teachers and offer help if and when necessary. Therefore, between having no time to collaborate and the need to do so, stress accumulates. 'The high ratings for this item is consistent with the findings of other studies' (Antoniou et al.; Kyriacou; Jacobsson et al.; Ralph et al.; Shu, 2003 as cited in Alghaswyneh 2011). But these findings contradicted with Khilafat and Zghool and Al-Yamani and Bu-Gahoos (as mentioned in Alghaswyneh 2011, p. 149). They found that relationships and poor cooperation with colleagues are not the primary sources of stress among teachers. In the same light, a study done by Eres \& Atanasoska (2011, p. 61 ) had made the same inferences.

Similarly, a study was done by Ekundayo and Kolawole (2013,p.313) on Stress Among Secondary School Teachers in Ekiti State, Nigeria, found out that $78,9 \%$ of the respondents responded poor relations with colleagues are sources of stress among teachers.

Regarding this source of stress, the semi-structured interviews revealed a number of teachers indicated that "poor relationship with colleagues" was the only aspect that made them feel pressure from colleagues. Jacobsson et al. (as cited in Alghaswyneh 2011) found that poor coordination between teachers is considered a vital predictor of teacher stress.

Other researchers echoed the same concern. Lack of support from other staff and lack of cooperation with colleagues (Antoniou et al.,2000), poor relationships with colleagues (Kyriacou, 1987; Johnstone, 1989; Travers and Cooper, 1996; Ralph et al., 2002; Hilo, 2004), and conflict with colleagues (Cockburn, 1996a) are considered a source of stress, (as cited by Alghaswyneh 2011, p. 149).

\subsection{Workload}

According to Kelly and Berthelsen 1995 \& Austin et al.2005 (as cited in Alghaswyneh 2011, p.206), 'workload means having too many tasks with too little time. He also cited Kyriacou 1987, who argued 'workload is not necessarily a big problem, but rather it's linked to stress'. Thus, is workload causing stress among teachers of Tsirang Dzongkhag.

Besides teaching students how to read, write, and speak, teachers in Bhutan have the arduous onus to perform. Their duties are incomplete if concerned only with daily teaching. They have to correct notebooks, prepare for the next day's lesson and coordinate extra co-curricular activities after school hours. The teachers in the remote schools have to take a minimum of 31 periods in a week despite shouldering other responsibilities assigned by the school management. By executing these many responsibilities, frustration, tiresome, tension and irritation, which are indeed synonyms of stress, will be there among teachers.

The above explanation is justified by Karaj \& Rapti (2013, p.17), who says that the correlation between time pressure $\&$ work overload and teacher stress is moderate, positive and significant $(\mathrm{r}=0.349, \mathrm{p}<0.01)$. Similarly, Mathews (2017, p. 55) remarked, "Less the teaching load the less stressful the teachers feel and the larger the teaching load, the more stressful the teachers feel."

\subsection{Performance Management System}

The fundamental goal of Performance Management is to promote and improve employee effectiveness. In school, it is a continuous process where principal and staff work together to plan, monitor and review the staff's work objective or goals and their overall contribution to the school. Though it was implemented solely for improving teachers' effectiveness through collaborative effort, teachers feel overwrought and nervous when their lessons are observed and activities are monitored and evaluated. As per the policy, the principal should attend a minimum of two teachers' lessons daily besides assessing their performances. Accordingly, ratings will be given for their promotions. But before the final ratings, lots of guidance and support, if needed, will be given to a teacher. Teachers who continue to underperform despite performance improvement plans and help given will be deprived of renewal of Teaching License (Teacher HR policy, as cited in Tashi 2014). Therefore, it is clear that the stress level among Bhutanese teachers is a steady and upward course. Unfortunately, no studies had been done on this particular topic to see whether it causes stress or not.

The causal relation between stress and teaching performance 


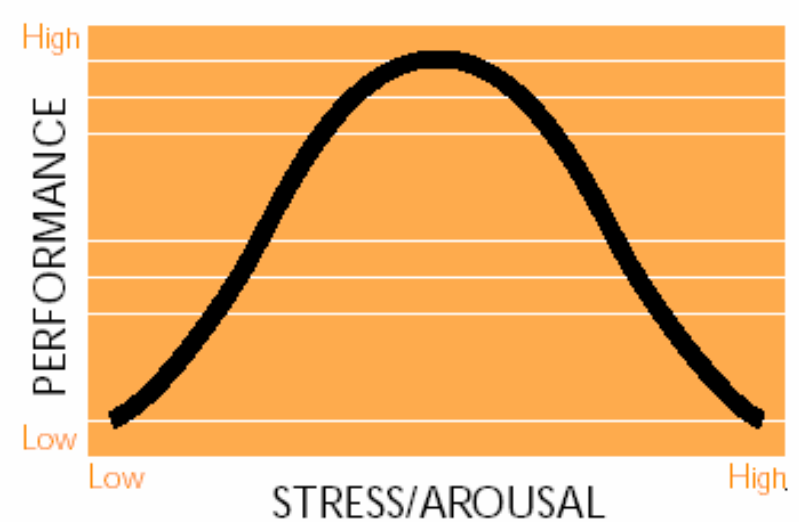

Fig: 4.1.1-Teachers stress

Source: teacher stress by Ken Mrozek

As the stress has both positive and negative effects, the performance at the developing stage of focus would have good work performances. But if the pressure is not coped up with proper interventions, it will have abysmal work performances in the long run. In reality, once we are stressed, our minds get disturbed. According to Ali, Ishtiaq \& Ahmad (2013, p.678), "The overstressed job decreases teachers performance and perhaps a chief contributor to a teacher dissatisfaction" in Punjab schools. From this, it is evident that teaching performances would be naturally low as almost all the teachers in the world are overstressed.

\section{DATA PRESENTATION AND ANALYSIS}

This section presents the data collected by the researcher through open-ended questionnaires. Questionnaires were given to primary teachers of Tsirang Dzongkhag in Bhutan. By using the purposive sampling technique, a total of 110 participants were selected. They participated freely, with no participant had been coerced to offer any contribution. The data so collected was thoroughly analysed to present the results accordingly.

\subsection{Participants' demographic}

Using the purposive sampling method, the researcher selected 110 participants; however, only 80 questionnaires have been received back for analysis. The demographics of these participants were as follows.

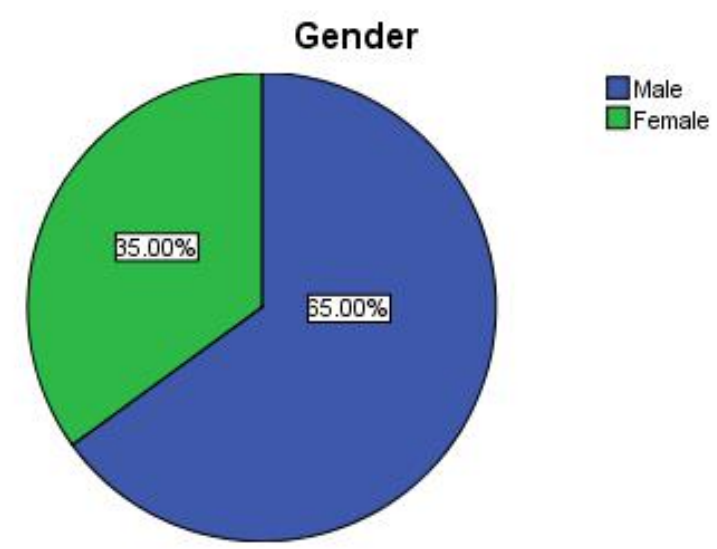

Fig: 5.1.1 - Gender of participants

Figure 5.1.1 above illustrates the gender of the selected participants; from the 80 participants chose, $35 \%$ of them were females, and $65 \%$ were males. The data indicates still male teachers dominate the teaching profession in primary schools in Dzongkhags, far away from the capital. This, therefore, shows male employees were more in comparison with their female counterparts.

5.2 No. of years in the service

Table: 5.2 .1

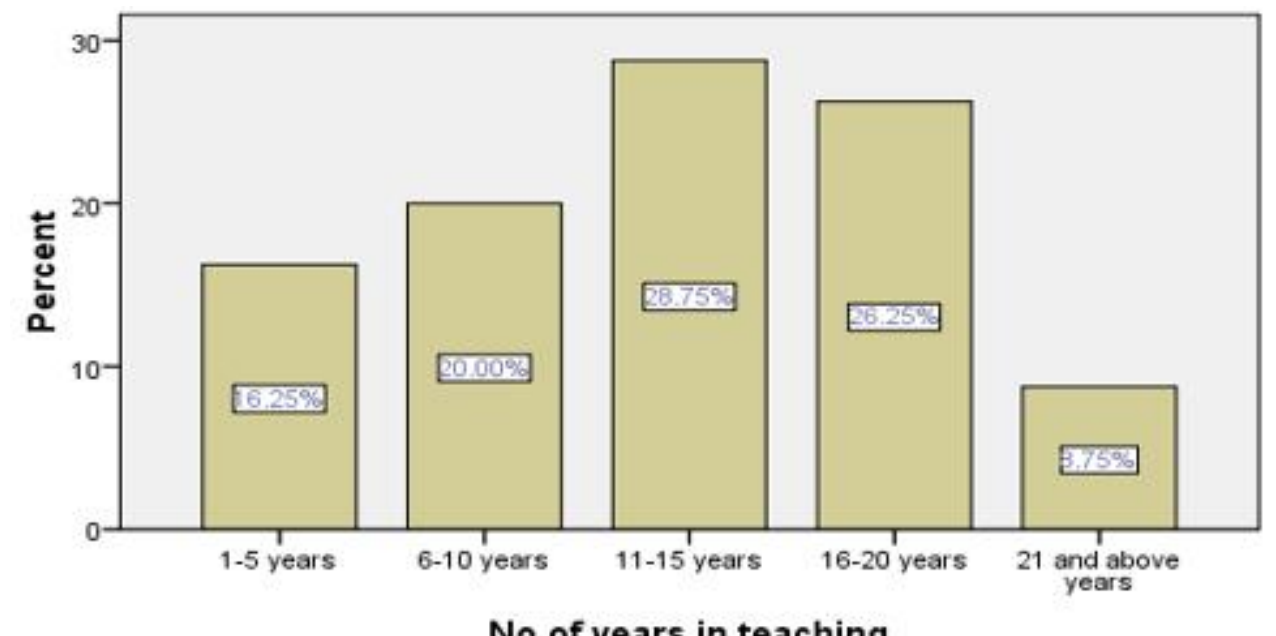

No of years in teaching 
From figure 5.2.1 above, a slight majority of the employees were from the teaching experience of 11-15 years, amounting to $28.75 \%$, whilst $26.25 \%$ of the employees were from the service experience range of 16 to 20 years. The figure also portrays that $20 \%$ were between 6 to 10 years and $16.25 \%$ of the employees formed the number of years in teaching 1-5 years, and $8.75 \%$ indicated above 21 years. Thus, a majority of its employees falls within the youthful and active employment zone. From the preceding, it is noteworthy to acknowledge that the researcher was very selective in choosing participants who have a long working experience or have worked with the institution for quite a long time. This is because those who have worked there for a long can give a better assessment than those with fewer years of experience.

\subsection{Academic Qualification}

Table: 5.3 .1

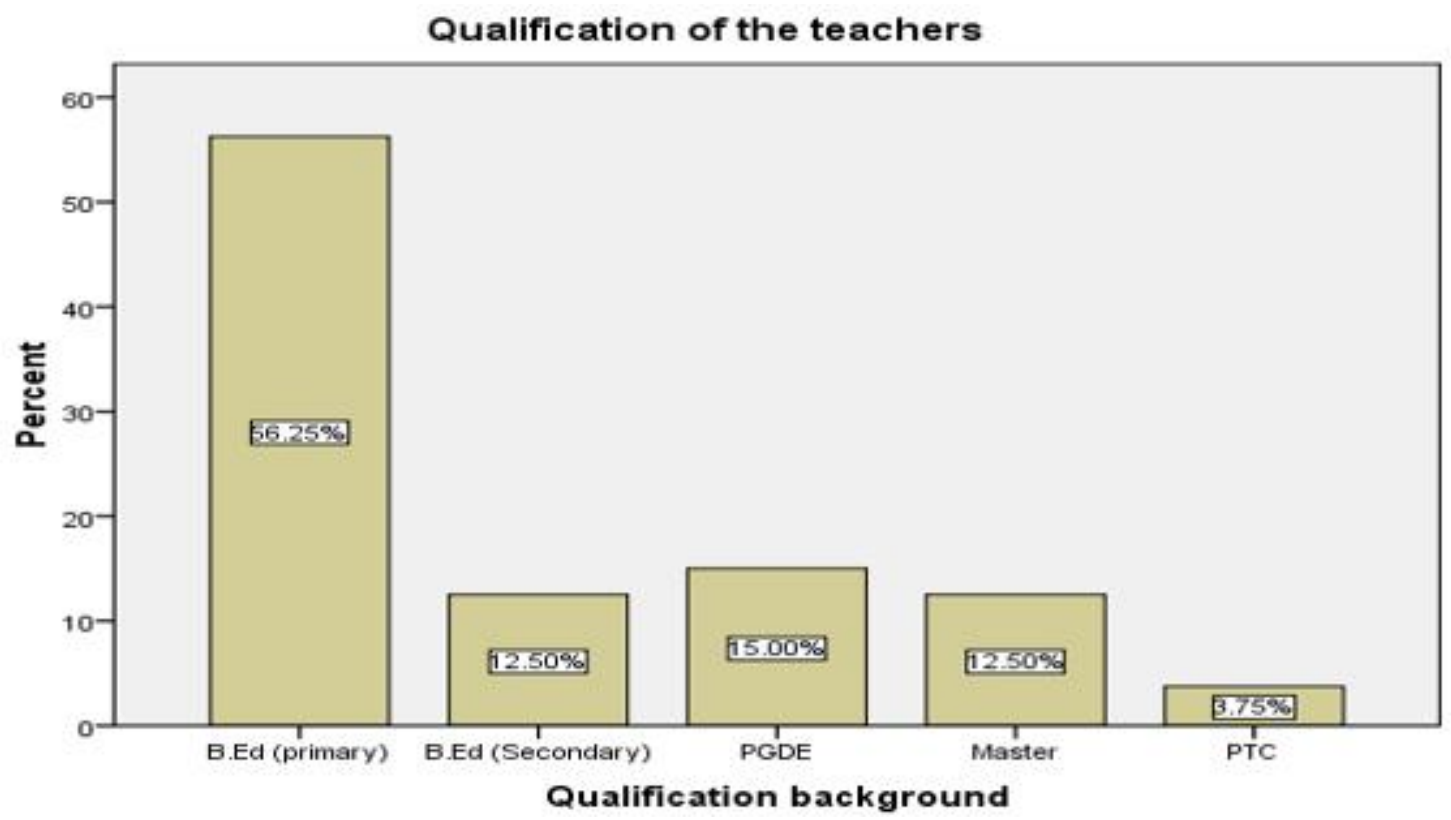

From table 5.3.1 above, it is seen that 45 teachers representing $56.25 \%$, have $\mathrm{B}$. Ed (primary) teaching background, whilst 12 of the teachers representing $15 \%$, have the PGDE professional background. This institution of higher learning ranges from Primary Teacher Certificate to Master.

\subsection{Teaching is a stressful job}

Fig: 5.4.1

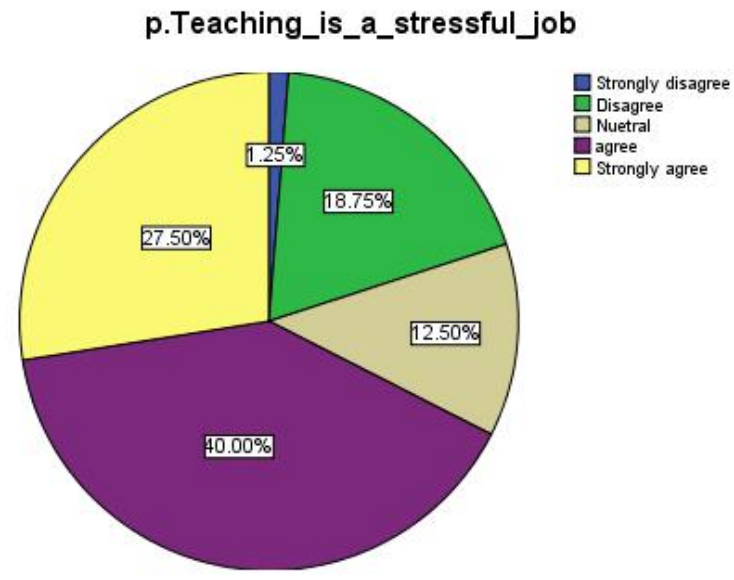

An overwhelming $67.5 \% \quad(\mathrm{f}=54)$ of primary school teachers of Tsirang Dzongkhag agreed that teaching is stressful. This has to do with the institution's mood and when there is a lot of pressure on them to brag about how productive they are to accomplish a given goal which is compounded by the multi-tasking job they have shouldered. Around $20 \%(\mathrm{f}=16)$ reported that they do not feel teaching is a stressful job.. The researchers could quickly notice that the participants who indicated it is not a tiresome profession might belong from the schools where there is no teacher shortage.

\subsection{I get time to relax with your family after school}


I get time to relax with my family after school

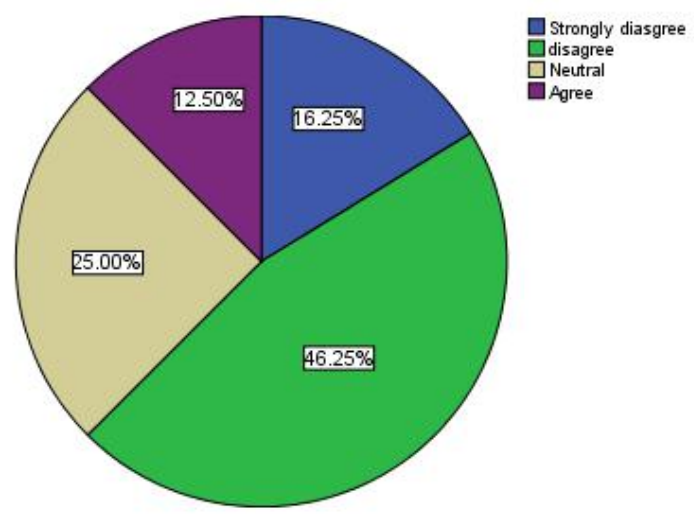

Fig: 5.5.1 families. About $62.5 \%$ of the primary teachers in Tsirang Dzongkhag disagreed that they get quality time spent with their family after school hours. The reason for not having quality time with their family is support strongly by the number of extra responsibilities shouldered apart from their primary roles as a teacher. The figure below shows that $29 \%$ of the teachers have shouldered more than five administrative responsibilities apart from teaching. Further, the analysis of an open-ended question also reveals that $61.2 \%(\mathrm{~F}=49)$ of the participants indicated that taking more responsibilities is one of the top factors that cause stress. Research on teacher duties by Harden and Crosby (2000) supports this viewpoint. According to the report, teachers must perform six tasks, and teaching is a complex and challenging career.

The figure above shows that primary school teachers do not get adequate time to spend meaningful time with their

Table: 5.5 .2

No of extra responsibilities a day

\begin{tabular}{|ll|c|c|c|c|}
\hline & Frequency & Percent & Valid Percent & $\begin{array}{c}\text { Cumulative } \\
\text { Percent }\end{array}$ \\
\hline Valid & Two responsibilities & 1 & 1.2 & 1.2 & 1.2 \\
& 3 responsibilities & 11 & 13.8 & 13.8 & 15.0 \\
& 4 Responsibilities & 19 & 23.8 & 23.8 & 38.8 \\
More than 5 responsibilities & 49 & 61.2 & 61.2 & 100.0 \\
Total & 80 & 100.0 & 100.0 & \\
\hline
\end{tabular}

\subsection{I get time to prepare lessons and correct notebooks}

As indicated in the table below, $70 \%$ of the participants disagree that they get adequate time to prepare their lesson plans and do the notebook corrections. However, $17.7 \%$ (F-15) acknowledge that they get sufficient time to prepare lessons and do the notebook corrections. In the same study on the changing roles of teachers, Valli and Buese (2007) discovered that teachers have to give increased attention to more classroom details and more time spent outside the classroom learning, planning, and justifying their actions to others (p. 523). As expressed by the participants in this study, teachers today have to show more than just their words. This expectation from all walks of life adds pressure to the teachers. Further, according to Berryhill et al. (2009), 80\% of instructors said they either didn't have enough time to accomplish chores connected to planning and assessment or had so many that it was difficult to do them all.

Table: 5.6 .1

I get time to prepare lessons and do note correction

\begin{tabular}{|cc|c|c|c|c|}
\hline & Frequency & Percent & Valid Percent & $\begin{array}{c}\text { Cumulative } \\
\text { Percent }\end{array}$ \\
\hline Valid & Strongly disagree & 21 & 26.2 & 26.2 & 26.2 \\
& Disagree & 35 & 43.8 & 43.8 & 70.0
\end{tabular}




\begin{tabular}{|c|c|c|c|c|}
\hline Neutral & 9 & 11.2 & 11.2 & 81.2 \\
Agree & 13 & 16.2 & 16.2 & 97.5 \\
strongly agree & 2 & 2.5 & 2.5 & 100.0 \\
Total & 80 & 100.0 & 100.0 & \\
\hline
\end{tabular}

\subsection{I get annoyed when students misbehave in the classroom}

Teachers typically indicated that students misbehaviour in the classroom is unbearable and stressful. They have had to devote a significant amount of time and energy to managing the classroom. Student misbehaviour impedes the smoothness and efficacy of instruction and the student's and classmates' learning. In consonant with the above statements, the table below shows that $53.8 \%$ of the respondents indicated that they get annoyed when students misbehave in the classroom, which is the root cause of their stress. Interestingly, $30 \%$ of teachers who took part in the study claimed that they neither agree nor disagree. A study conducted by Hastings and Bham (2003) reported that students blame most of a teacher's stress. According to the survey, disrespect, a lack of social ability, and a lack of focus are the primary reasons student behaviour causes teachers stress. However, only $49 \%$ of the participants in this study recognised student behaviour as a significant source of stress.

Table: 5.7 .1

I feel annoyed when students misbehave in the classroom

\begin{tabular}{|l|r|r|r|r|}
\hline & Frequency & Percent & Valid Percent & $\begin{array}{c}\text { Cumulative } \\
\text { Percent }\end{array}$ \\
\hline Valid $\quad$ Strongly disagree & 3 & 3.8 & 3.8 & 3.8 \\
& 10 & 12.5 & 12.5 & 16.2 \\
Disagree & 24 & 30.0 & 30.0 & 46.2 \\
Neutral & 39 & 48.8 & 48.8 & 95.0 \\
Agree & 4 & 5.0 & 5.0 & 100.0 \\
Strongly agree & 80 & 100.0 & 100.0 & \\
Total & & &
\end{tabular}

\subsection{Performance Management System (PMS) increases my stress}

PMS is a school-wide continuous improvement strategy that gives schools and Dzongkhags the tools they need to control their performance. The PMS principle promotes transparency in school performance while focusing on educational quality and increasing access to education for all students. However, there has been misconception and misinterpretation of the new system, although in practice since 2013. Many teachers considered PMS an overburdened workload because teachers have to keep records of other activities besides daily lesson planning, book correction, and teaching-learning materials. One of the critical concerns raised by participants about administration was the frequent implementation of new processes. Thus, to ascertain the opinion of teachers on PMS, data was collected from primary school teachers of Tsirang Dzongkhag. The table below indicated that $21.3 \%$ of the participants disagree that the performance management system is good, increasing their stress level. The participants in the study also discussed what Kyriacou (2001) described as a frequent change in the policy. This refers to teachers' stress levels can be increased by being exposed to a lot of change and having difficult or complex interactions with colleagues and administration. Surprisingly, $37.5 \%$ of the primary school teachers of Tsirang neither agree nor disagree with the above question. The remaining $41.2 \%$ of the participants acknowledge that PMS does not influence the stress level. 
.Table: 5.8 .1

The performance management system is good

\begin{tabular}{|l|r|r|r|r|}
\hline & Frequency & Percent & Valid Percent & $\begin{array}{c}\text { Cumulative } \\
\text { Percent }\end{array}$ \\
\hline Valid $\quad$ Strongly disagree & 3 & 3.8 & 3.8 & 3.8 \\
Disagree & 14 & 17.5 & 17.5 & 21.2 \\
Neutral & 30 & 37.5 & 37.5 & 58.8 \\
Agree & 28 & 35.0 & 35.0 & 93.8 \\
Strongly agree & 5 & 6.2 & 6.2 & 100.0 \\
Total & 80 & 100.0 & 100.0 & \\
\hline
\end{tabular}

\subsection{Stress and occupational performance is related}

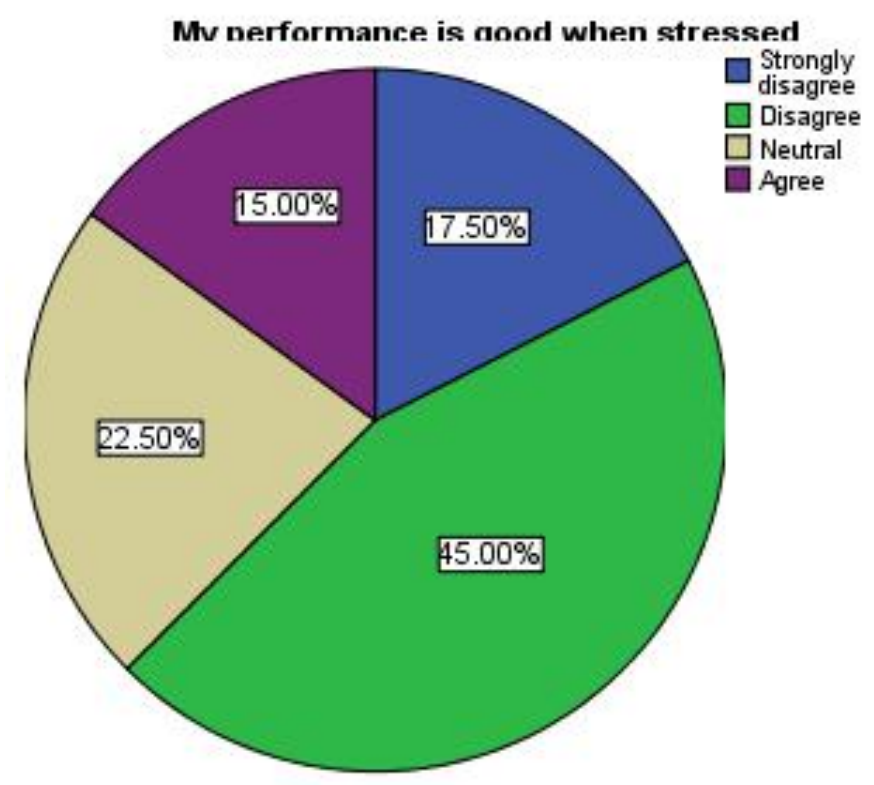

Fig: 5.9.1

The above figure shows that more than $45 \%(\mathrm{f}=36)$ and $17.50 \%(\mathrm{f}=14)$ respondents respectively remarked that they disagree with the statement, "my performance is good when stressed.' This indicates that more than half of the 80 participants who took part in the study view that their performance is badly affected when under stress. This finding is consonant with Skinner et al. (2018), which reported that a teacher's poor job performance is due to stress, leading to distress and despair. Most importantly, low self-efficacy may be attributed to rising stress levels in urban educators, negatively affecting their relationships, wellbeing, and teacher and student performance. Contrary to the above responses, $15 \%$ believed they could work well under stress or pressure better. Thus, the researchers believe that teachers who have less than two periods a day make up $15 \%$ of the research participants.

\subsection{Qualitative data analysis: Focus Group Discussion}

Data analysis might be complicated due to the magnitude and complexity of qualitative data obtained from a sample of varied respondents. Diversity, on the other hand, can produce a wealth of information. This study used thematic coding to transform most textual data into codes classified into favourite thematic clusters. This technique assisted the analysts in condensing the textual information into five primary topic clusters, each having a frequency of data units. The four critical causes of teachers' stress are 
workload, misbehaviour, leadership style and unstable policy and system. A study conducted by Turna (2014) also supported that demotivated students, workload, disciplinary environment, problems with co-workers, administrative reasons, conflict of duties, and unacceptable working conditions are among the various sources of stress affecting teachers.

\subsubsection{Workload}

The participants in both the focus group mentioned that teachers are constantly put under stress. Teachers are required to fulfil various tasks for their students, which is especially true in primary schools. Teachers at primary schools play nurse, nurture young children, tie shoes, teach pupils how to use the restroom and walk in a line, and give students a fundamental basis for school. "With so many numerous tasks that we play as instructors, [it] adds to our stress," participants said, and "how are we [teachers] supposed to provide that background while teaching at the same time?" they wondered. Because of these multiple roles, they have to shoulder they are overburden to work leading to stress. One of the participants in FGD remarked, "As a principal, I had to do many things apart from teaching. And running a school where we have many students as boarding from PP-X is again more stressful." The participants' opinion further supports this, "Every added responsibility needs extra time, energy and dedication. This naturally contributes to more stress." Participants were also concerned about how difficult it is when children do not achieve well despite the teacher's efforts. One teacher participant suggested that teacher's workload should be minimised to bring effective performance. The quantitative and qualitative data revealed that today's most significant stressors facing primary school teachers are the workload and too many responsibilities. A study conducted by MacBeath (2008) supports the above finding, which states, "Teacher demands have increased beyond the capacity to meet them." This study also discovered that, as a result, teachers' working weeks have raised and that 12-hour workdays and weekend schoolwork are no longer uncommon practices for teachers. That study revealed that teachers are overly concerned with excessive paperwork requirements and an increased workload and time constraints.

\subsubsection{Student's misbehaviour}

According to the qualitative research finding, an issue that teachers have experienced is classroom behaviour. According to the research conducted by Göksoy and Argon (2014), disciplinary/problematic behaviours, academic incompetence, being unprepared/ irresponsible, and disinterest were all mentioned as sources of stress for teachers as a result of students. In this study, participants expressed that "Student's misbehaviour disturbs whole class and we need to take action for that whereby we sometimes need to skip the ongoing teaching in the middle."

According to Hastings and Bham (2003), students are to blame for most of a teacher's stress (p.116). According to this report, disrespect, a lack of social ability, and a lack of focus are the primary reasons for teachers' stress. At least $49 \%$ of the participants in this study said that student behaviour was a significant source of stress. The participants also reiterated that student misbehaviours lead to disturbance in teaching and learning, which affects the teacher's mental health. The prohibition of corporal punishment may be one of the reasons why student misconduct is on the rise in the classroom. If teachers correct students, they will almost certainly be dismissed by their parents. The other setback is the policy of corporal punishment, which instructors blame for the deplorable behaviour of school children. However, articles 109 and 111 of the Penal Code 2004 provide a defence for using force by parents and others in disciplining children. The near-universal acceptance of corporal punishment in children necessitates clarity in law that no degree or kind of corporal punishment is lawful, however light. These articles should be explicitly repealed and corporal punishment prohibited in all settings, including the family home.

\subsubsection{School system and Education policy}

According to participants' opinions, sources of stress affecting teachers originate from the school system and education policy. It is thought-provoking that although teachers are paid handsomely by the current government to retain and reward their services, many wished to leave the profession. This indicated that pay and allowance are not the factors that make teachers go their careers. The qualitative data analysis gathered through FGD revealed that stress factors are the schools' system and the education policy. Around $30 \%$ of the primary school teachers remarked that systems such as Bhutan Professional Standards for Teachers (BPST), School Performance Management System (SPMS) and Individual Work Planning (IWP) add stress which affects their productivity. One of the participants said, "The six domains in SPMS to be fulfilled is a hectic task. Besides teaching, we have to shoulder many other responsibilities to fulfil SPMS indicators." The documentation requirement as per IWP and BPTS having to prove everything was an added and unwanted stressor for teachers.

The study also found that too many policies demands coming too fast often resulted in teacher discouragement 
and stress. The participants also remarked, "Teacher's work as teaching is not a stressful job, but other responsibilities of IWP makes it stressful." An IWP, which is a subset of "Managing for Excellence" (MaX), was instituted by RCSC in 2014 to strengthen the existing Performance Management System (PMS) to ensure organisational effectiveness by cascading institutional accountabilities to the various levels of the organisation's hierarchy and overall performance by differentiating performer from non-performer. But it did not happen the way it was expected. Managers and principals use an IWP rating and moderation process that is ambiguous and lacks substance. The instructor may be excellent at teaching, but they are only rated good because they can keep records according to IWP.

In contrast, a teacher who cannot keep records may be rated outstanding owing to his documentation ability. The abstract nature of IWP assessment standards, assessor partiality, nepotism, and a lack of leadership responsibility on the part of principals, adds to teachers' stress. In support of the above findings, one of the participants remarked, "Besides working hard, we can't fulfil IWP target as the targets for IWP need high." Berryhill et al. (2009) found that eighty per cent of teachers reported having either limited time to complete tasks related to accountability policies or having so many accountability related functions that it was challenging to meet them (p. 6-7).

\subsubsection{Leadership style}

The qualitative data analysis found that many teachers believe that leadership styles substantially impact some people's lives. They also thought that a leader is the most potent profession, and if the leader doesn't execute well, all other systems will be affected. The principal (participant) in one of the primary schools stated that teaching and managing school is stressful. The study's finding conducted by Hysa, F (2018) also confirms that leadership styles directly impact teacher stress at work. According to the results, those who did not exert authoritative leadership recognition and qualifications for school administration lacked experience or had a negative experience embedded in their way of thinking and school leadership styles. They also feel less stress if their leader is supportive, who looks after their welfare. Teachers aren't recognised or revered as much as they should be, according to the participants. "I don't think people realise how much effort we do," one participant stated, while another remarked, "I don't feel valued at all." People do not comprehend how difficult it is to teach a classroom full of young learners with today's demands; thus, participants frequently feel neglected. In a study on teacher stress conducted by Howard and Johnson (2004), this same sense of powerlessness was seen.
According to the survey, teachers experience undesired stress when the administrative structure is hierarchical and centralised in the hands of a few people. According to the study, teachers are also stressed when the principal has an autocratic leadership style (p. 408).

\subsubsection{Stress coping strategies}

The second question appears in the form to determine the approach to cope with the stress, which is as follows: "What kind of support do teachers need to reduce their stress?" The most prominent codes created in correlation with strategies of coping with stress for teachers working in the primary schools of Tsirang have been broadly categorised into six coping methods as follows:

a) Reduce the number of periods and job responsibility $(35 \%)$

b) Maintain a teacher-student ratio of 1: 24 (25\%)

c) Recruit enough teachers to share the workload $(10 \%)$

d) Supportive and good school leaders (17.5\%)

e) Create a conducive working environment (12.5\%)

A study conducted by Sprenger (2011) also discussed the same stress management strategies such as reducing administration works and other responsibilities, encouraging democratic leadership style, inward systems (nap, silence, and religion) and supportive friends and leaders.

\section{CONCLUSION AND RECOMMENDATION}

The teaching career can be a demanding one. Most teachers would agree that regular contact with children, parents, and co-workers and the ongoing demands of teaching can lead to excessive expectations and obstacles, which can negatively impact job performance. This study aimed to evaluate how work stress affects teachers' performance in primary schools in Tsirang Dzongkhag. The number of factors discovered and presented and the literature review shows that the study's goal was accomplished. This study's hypothesis (Achu, C. 2012) suggested that when stress reaches a specific unfavourable level, it has a negative impact on teachers performance.

The findings of this study are summarised, and broad inferences are drawn based on the results and analyses. The data were analysed in frequency and percentages, and conclusions were drawn based on the findings. The scientific study of the data was made more accessible with the use of diagrams. Teachers' performance is going to suffer as a result of excessive work-related stress. The participants recognise several causes of stress: teacher 
workload, student behaviour, education policy and policy, and leadership style.

The stress management strategies which the participants suggested must be practised and implemented mindfully. Furthermore, management should implement an Employee Assistance Program, a proactive tool that identifies and intervenes on problems before impairing teachers' productivity. Praise and appreciation have long been acknowledged to have a positive impact. The practice of praising and recognising an employee for excellent performance should be instilled by management through awards, merit systems, and other benefits or bonuses. The other action that the Education Ministry must take immediately is to maintain the correct ratio of teacherstudents (1:24), which will help curb students' misbehaviour and reduce teachers' workload. The need to review IWP and BPST is also felt as many discrepancies happened during evaluation and moderation. The right and deserving employees are not rewarded due to inconsistency of program implementation. Since the jobrelated stress from lack of support from supervisors in tough times and workload conflict was high among teachers, the school administration should solve these issues.

Occupational stress is an integral part of life. Hence, further study can be undertaken to devise effective programmes to reduce work stress in which the present study remains inadequate. This study was limited to schools in Tsirang Dzongkhag only. However, investigations can provide helpful insight into the patterns of stress levels among various occupations. Practical studies can be conducted by comparing intra-professional groups such as primary and higher secondary school teachers or private and government-employed teachers.

\section{ACKNOWLEDGEMENT}

First and foremost, we owe our gratitude to our families for their unwavering support and encouragement, without which this research would not have been possible. We want to thank Mr Sangay Tshewang (Principal) of Technical Training Institute, Samthang; Wangdue Phodrang for his excellent time, insight, and expert guidance over the last five months. His patience, support, and belief in our talents have inspired us to accomplish this project effectively.

We also thank the contributions of others who contributed to the accomplishment of this research project. We would also like to extend the principals and personnel of the primary schools in Tsirang Dzongkhag for their involvement in the FDG and survey questionnaire; and our
Dzongkhag Education Officers for their assistance, availability and readiness to assist us.

\section{REFERENCES}

[1] Achu, C. (2012). The relationship between work stress and performance in a public sector service organisation. School of Management Sciences, Varanasi, New Delhi, India.

[2] Ahmed A. \& Ramzan, M. (2013). Effects of Job Stress on Employees Job Performance: A Study on Banking Sector of Pakistan, IOSR Journal of Business and Management, Vol. 11, Issue 6 pp 61- 68.

[3] Alghaswyneh, S.A. (2011), Teacher stress among Tawjihi Teachers in Jordan \& Their Adopted Coping Strategies to Reduce Stress, Degree of Doctor of Philosophy, University of Huddersfield, Jordan.

[4] Ali, k., Ishtiaq, I., Ahmad, M.( 2013), Occupational Stress, Effects and Job Performances in the Teachers of Schools of Punjab (Pakistan), International Journal of Academic Research in Business \& Social Science, vol. 3, no. 11, pp. 665 - 680, viewed October 102015.

[5] Berryhill, J., Linney, J.A., \& Fromewick, J. (2009). The effects of education accountability on teachers: Are policies too stress provoking for their own good? International Journal of Education Policy and Leadership, 4(5), 1-14.

[6] Chan, D. W. (1998). Stress, coping strategies, and psychological distress among secondary school teachers in Hong Kong. American Educational Research Journal, 35(1), 145- 163.

[7] Darmody, M., \& Smyth, E. (2016). Primary school principals job satisfaction and occupational stress. International Journal of Educational Management, 30(1), 115-128. https://doi.org/10.1108/ijem-12-2014-0162

[8] Dyck, D. 2001, "The toxic workplace", Benefits Canada, 52.

[9] Ekundayo, H. T., \& Kolawole, A. O. (2013). Stress Among Secondary School Teachers in Ekiti State, Nigeria. Journal of Educational and Social Research, 01 .https://doi. Org/10.5901/jesr.2013.v3n2p311

[10] Eres, F., Atanasoska, T. (2011), Occupational Stress of Teachers: A Comparative Study between Turkey and Macedonia', International Journal of Humanities and Social Science, vol. 1, no. 7, pp. 59-65.

[11] Göksoy, S. and Argon, T. (2014). Inhibitory and Supportive sources of stress for teachers in schools. Journal of Teacher Education and Educators, Volume 3, Issue 2, 245-271.

[12] Guglielmi, R. S., \& Tatrow, K. (1998). Occupational stress, burnout, and health in teachers: A methodological and theoretical analysis. Review of Educational Research, 68(1), 61- 99 .

[13] Harden, R.M. \& Crosby, J. (2000). The good teacher is more than a lecturer- the twelve roles of the teacher. Medical Teacher, 22(4), 334-347.

[14] Harris, G. (2011). Individual stress management coursework in Canadian teacher preparation programs. Canadian Journal of Education, 34(4), 104-117. Retrieved from 
http://ojs.vre.upei.ca/index.php/cjerce/article/view/723/110 $\underline{4}$

[15] Harris, K. J., Wheeler, A. R., \& Kacmar, K. M. (2009). Leader-member exchange and empowerment: Direct and interactive effects on job satisfaction, turnover intentions, and performance. Leadership Quarterly, 20, 371-382.

[16] Hastings, R., \& Bham, M. (2003). The relationship between student behaviour patterns and teacher burnout. School Psychology International, 24(1), 115-127.

[17] Hartney, E. (2008). Stress management for teachers. London: Continuum International Publishing Group

[18] Howard, S., \& Johnson, B. (2004). Resilient teachers: Resisting stress and burnout. Social Psychology of education, 7, 399-420.

[19] Hysa, F. Vol 4, No 3 (2014)-Articles School Management and Leadership in Education.

[20] Karaj, S., Rapti, E. (2011), Teacher Job Stress in Albania, Examining the Role of Students: Classroom Disruptive Behavior \& Other Factors in the School Context, Problems of Education in the $21^{\text {st }}$ Century, vol. 54.

[21] Khan, A \& et al. (2012), Teachers Stress, Performances \& resources The Moderating Effects of Resources on Stress and Performances, International Review of Social Science \& Humanities, vol.2, no. 2, pp. $21-29$.

[22] Kobasa, S. C., Maddi, J., Ouccelli, M., \& Zola, M. C. (1985). Effectiveness of hardiness, exercise and social support as resources against illness. Journal of Psychosomatic Research, 29, 525- 533.

[23] Kyriacou, C. (2001). Teacher stress: Directions for future research. Educational Review, 53(1), 27-35.

[24] Lim Ji Yoon, (2014). The Effects of Teachers' Emotional Labor on Job Stress, Burnout and Teacher-efficacy. The Journal of Korean Teacher Education, 31(1), 197-220. https://doi.org/10.24211/tjkte.2014.31.1.197

[25] Lorin. (2015). Analysing the effect of teachers' creativity education on students academic achievement in secondary schools. International Journal of Advanced Biological and Biomedical Research, 3(4), 326-331. https://doi.org/10.18869/ijabbr.2015.326

[26] Lusaka Urban Schools, Degree of Master of Educational Psychology, University of Zambia, Lusaka.

[27] MacBeath, J. (2008). Pressure and Professionalism. Retrieved March 10, 2011, from 74 www.admin.cam.ac.uk/news/dp/2008032009.

[28] McTernan, W. P., Dollard, M. F., \& LaMontagne, A. D. (2013). Depression in the Workplace: An economical cost analysis of depression-related productivity loss attributable to job strain and bullying. Work \& Stress, 27(4), 321338. https://doi.org/10.1080/02678373.2013.846948

[29] Makasa, J.W. (2013), Perceived Level of Occupational Stress among Basic School Teachers: A Case Study of Selected teachers.

[30] Mathews, J. (2017). Occupational Stress and Job Burnout among Primary and Secondary School Teachers in Cuttack, Orissa, 2013. International Journal of Indian Psychology, 5(1). https://doi.org/10.25215/0501.056

[31] Naidoo, K., Botha, C. J., \& Bisschoff, C. A. (2013). Causes of Stress in Public Schools and its Impact on Work
Performance of Educators. Journal of Social Sciences, 34(2), 177-190. https://doi.org/10.1080/09718923.2013.11893129

[32] Nyambongi, P.M.( 2013), Causes of Stress among Teachers in Public Schools: A case of Public Secondary Schools in Starehe district', Degree of Executive Masters of Business, Kenyatta University.

[33] Ramaiah, k., \& Ramchandram, v. (2021). Occupational stress among high school teachers. Global Journal for Research Analysis, 41-43. https://doi.org/10.36106/gjra/3109173

[34] Royal Government of Bhutan (2004). Penal Code of Bhutan. Thimphu.

[35] Scheier, M. F., \& Carver, C. S. (1985). Optimism, coping and health: Assessment and implications of generalised outcome expectancies. Health Psychology, 4, 219- 247.

[36] Skinner, B., Leavey, G., \& Rothi, D. (2018, December 4). Managerialism and teacher professional identity: Impact on wellbeing among teachers in the UK. Educational Review, [CEDR 1556205] 1-16. Identity impact-on-wellbeing. DOI: 10.1080/00131911.2018.1556205

[37] Sprenger, J. (2011), Stress and Coping Behaviors Among Primary School Teachers, Degree Master of Arts, East Carolina University.

[38] Suyanto \& et al. (2021). Factors Affecting Work Stress And Performance With Compensation Moderation In Working Load Relationships On The Performance Of Private Teachers In East Kalimantan. Psychology and Education Journal, 58(1), 2398-2411. https://doi.org/10.17762/pae.v58i1.1115.

[39] Tashi, K. (2014), Occupational Stress among Bhutanese Teachers, Asian Journal of Management Science and Education, vol. 3, no. 2, pp. 71- 79.

[40] Turna, H. (2014). Stress resources and coping methods with stress for teachers (The example of Edirne province/ Keşan. Master Thesis), Okan University, Istanbul. Retrieved from: http://tez2.yok.gov.tr/.

[41] Usman, A et al. 2011, 'Work Stress Experienced by the Teaching Staff of University of Punjab, Pakistan Antecedents and Consequences', International Journal of Business \& Social Science, vol. 2, no. 8, pp. $202-210$.

[42] Valli, L. \& Buese, D. (2007). The changing roles of teachers in an era of high stakes accountability. American Educational Research Journal, 44(3), 519-558.

[43] Zedan, R. (2012), Stress and Copying strategies among Elementary School Teachers in Isreal', Universal Journal of Education \& General Studies, vol. 1, no. 9, pp. 265 278. 